\title{
AS RELIGIOEES NO BRASIL E O CENSO DE 2010: NOTAS EM TORNO DO ARTIGO NÚMEROS E NARRATIVAS, DE CLARA MAFRA
}

Paulo Fernando Carneiro de Andrade ${ }^{1}$

O artigo Números e Narrativas, de Clara Mafra, aborda algumas questões fundamentais sobre o Censo de 2010 e as religiōes no Brasil. Tecerei aqui algumas observações sobre três pontos:

1. A qualidade dos dados a partir da coerência da série histórica dos Censos.

2. A questão do decréscimo relativo dos católicos.

3. A nossa diversidade religiosa e os "sem religião".

\section{A QUALIDADE DOS DADOS A PARTIR DA COERÊNCIA DA SÉRIE HISTÓRICA DOS CENSOS}

Muitas vezes, os dados do Censo são questionados por algumas lideranças religiosas porque elas não encontram correspondência entre a imagem que fazem de sua religião e os dados que se revelam no Censo. Clara Mafra traz algumas problematizações bastante pertinentes à "tecnologia da produção do número", mas ao mesmo tempo afirma a "importância e a relevância da tecnologia do Censo do IBGE”. Temos no Brasil uma série histórica de dados do Censo, bastante relevante e com notável coerência. O trabalho feito pela equipe do IBGE de cotejar os dados e interpretar possíveis discrepâncias na consolidação dos resultados tem produzido informações sobre a filiação

1 Professor da PUC-RJ. Doutor em Teologia pela Pontifícia Universidade Gregoriana de Roma. Decano do Centro de Teologia e Ciências Humanas da PUC-RJ. E-mail: paulof@puc-rio.br 
religiosa que, quando comparadas na sucessão de anos, não demonstram flutuações que permitam colocar em questão os números obtidos. Podemos citar como exemplo o número de pessoas que se declaram pertencentes às religiões afro-brasileiras na Bahia e no Rio Grande do Sul no Censo de 2000. Alguns manifestaram estranheza com o fato de o número ser maior no Sul que na Bahia. Os mesmos números, entretanto, com pequenas variações, se repetem no Censo de 2010.

Aqui cabe outra observação. Afinal, o que o Censo mede? O Censo nos dá um quadro, relativamente bom, das respostas dadas pelas pessoas à pergunta "qual a sua religião?". Ao responder a essa pergunta podemos dizer que a pessoa, de algum modo, se coloca em relação com as instâncias do "eu ideal" e do "ideal do eu". Por "eu ideal" entendemos, como Lacan, a autoimagem idealizada do sujeito, ou seja, como eu idealmente me considero ser, e pertence ao registro do imaginário. Por sua vez, no "ideal do eu”, que pertence ao registro do simbólico, encontra-se a Ordem Simbólica, o Grande Outro, a quem eu quero satisfazer com minha imagem, a quem quero impressionar. Em outras palavras, a resposta simultaneamente afirma como eu me imagino ser, como penso ser visto pelos outros, mas, também, como quero ser socialmente visto. A resposta não mede quantas pessoas frequentam as missas, os cultos, os terreiros. Tampouco o Censo se debruça sobre o conteúdo concreto da crença do entrevistado, mas apenas pede dele que responda à pergunta "qual a sua religião?”. No entanto, como Clara Mafra afirma, o que o Censo mede, isto é, a resposta à pergunta: "qual a sua religião?", é significativo e não pode ser desqualificado, devendo ser compreendido em sua dimensão própria.

Sob esta perspectiva, cabe uma nota sobre a chamada "dupla pertença". Creio ser necessário abrir um espaço maior de reflexão sobre a qualificação que fazemos das pessoas que frequentam, com certa regularidade, dois espaços religiosos diversos como tendo "dupla pertença". Como Clara Mafra chama a atenção em seu artigo, o número de pessoas que responderam como "múltiplos pertencimentos" é muito baixo (apenas 15.379!). Será que isso se deve exclusivamente a uma falha na pergunta, que impossibilitaria ao Censo detectar as duplas e múltiplas pertenças? Não podemos também pensar que, para muitos, o que chamamos de dupla ou múltipla pertença não seja talvez entendido 
assim? Como essas pessoas se veem e querem ser vistas? Como compreendem sua vivência religiosa? Não nos ajudariam a repensar essa questão as categorias de hibridismo e tradução, desenvolvidas no âmbito dos chamados "Estudos Culturais", mais do que as de sincretismo e dupla pertença?

\section{A QUESTÃO DO DECRÉSCIMO RELATIVO DOS CATÓLICOS}

Um dos pontos mais relevantes dos resultados dos últimos Censos encontra-se no acelerado processo de desfiliação católica que se observa, sobretudo, nas últimas duas décadas e no expressivo crescimento do grupo evangélico e dos que se declaram "sem religião".

Esse decréscimo, embora possa ser compreendido como parte do processo de secularização, como abordarei adiante, não deve, entretanto, ser minimizado. No Censo de 2010 temos, pela primeira vez, uma diminuição não só em termos relativos, mas também em números absolutos, daqueles que se declaram católicos. Pela primeira vez também o número dos que se declaram católicos é maior entre homens $(65,5 \%)$ do que entre mulheres $(63,8 \%)$, e maior entre a população em geral do que entre jovens de 15 a 29 anos $(63,4 \%$ de jovens contra $64,6 \%$ da média geral e $75,2 \%$ no grupo que possui 80 anos ou mais). Esse fato tem um significado importante. Se considerarmos que em todas as outras áreas do cristianismo - e nas outras religiōes - a presença das mulheres é maior do que a dos homens, com exceção dos que se declaram sem religião, e o fato de que normalmente as mulheres têm uma vivência religiosa mais expressiva, podemos inferir que o catolicismo perde fiéis mais entre o núcleo praticante do que entre aqueles católicos normalmente classificados como nominais, isto é, que possuem uma relação menos intensa com as práticas regulares da Igreja (frequência semanal ou ao menos regular aos sacramentos, por exemplo). As mulheres estão deixando o catolicismo atrás de novas vivências religiosas, mais do que os homens que, por possuírem em maior número uma relação religiosa que não supõe um maior engajamento eclesial ou sacramental, continuam a se declarar católicos como tradicionalmente o faziam. O fato de o número de jovens ser menor do que a média da população significa, por sua vez, uma

Debates do NER, Porto Alegre, ANo I4, N. 24, P. 93-98, JUl./DeZ. 2013 
maior dificuldade de reposição futura, o que, aliado ao papel importante que a mãe tem na formação da identidade religiosa das crianças, não nos leva a poder traçar um bom prognóstico do futuro do catolicismo entre nós, se não houver uma mudança significativa. Isso não quer dizer, entretanto, que os dados atuais possam ser extrapolados e que o Brasil se tornará brevemente uma nação majoritariamente evangélica. Os dados não permitem extrapolações, sendo mais possível que nas próximas décadas ocorra certa estabilização dos números; porém a Igreja Católica encontra-se diante de um grande desafio pastoral e não pode relativizar essa perda afirmando que os que se desfiliam seriam apenas os católicos de menor participação eclesial, os chamados "católicos nominais", e que sua perda seria de pouca relevância para a instituição.

\section{A NOSSA DIVERSIDADE RELIGIOSA E OS “SEM RELIGIÃO”}

O processo de secularização parece ter destinos diferentes na Europa e nas Américas. Enquanto na Europa ele levou a um forte crescimento do ateísmo, com o consequente ofuscamento da religião, nas Américas (Sul e Norte) ele levou a um aumento do trânsito e da diversificação religiosa, permanecendo o ateísmo em níveis relativamente baixos. No caso brasileiro, o que se constata pelo Censo é um grande decréscimo do catolicismo, que antes era totalmente hegemônico, sem que isso implique uma descristianização de nossa cultura. Embora em nosso imaginário social nos vejamos como um povo religioso e diversificado em nossas crenças e práticas, $86,8 \%$ da população continua a se declarar cristã, o que, somado aos $8 \%$ que se declaram sem religião, perfaz $94,8 \%$. Apenas $5,2 \%$ da população declara ter outra religião que não a cristã. Impressiona o fato de que esse número é mais ou menos invariável, tendo ocorrido, em termos absolutos, apenas uma pequena variação nas últimas décadas. É também digno de nota que, quando agregamos a parcela católica com a evangélica e com a dos "sem religião" em diferentes regiōes, inclusive em municípios ou estados onde o catolicismo é mais forte, ou onde os evangélicos são mais fortes, ou ainda onde temos um maior percentual de "sem religião", continuamos quase sempre a ter uma soma que perfaz entre 92 e $95 \%$ da população, excetuando-se obviamente municípios de forte imigração oriental.

Debates do NER, Porto Alegre, ANo I4, N. 24, P. 93-98, JUl./DeZ. 2013 
Em outras palavras, somos menos diversos do que nos imaginamos, ao menos nas respostas dadas à pergunta "qual a sua religião?". O que é notável é a diversificação por que passou o cristianismo e o fato de que essa diversificação continua a crescer, não só com o processo de desfiliação católica, mas também com o surgimento de novas igrejas e denominações cristãs e com um processo fluido que faz com que igrejas que vinham apresentando forte crescimento, como a Universal do Reino de Deus, apresentem subitamente sinais de declínio, ainda que, como Clara Mafra assinalou, esse decréscimo não seja necessariamente um sinal do esgotamento de seu modelo.

O percentual de pessoas que se declaram "sem religião" é de $8 \%$, sendo que apenas $0,3 \%$ se declara ateu. O grupo dos que se declaram "sem religião" teve na década um crescimento em termos relativos de cerca de $10 \%$, mas em termos absolutos incorporou neste período apenas mais $0,7 \%$ da população. Dado o processo de secularização e de desfiliação, podia-se esperar nas duas ultimas décadas um crescimento maior. Nos Estados Unidos, segundo os dados do Pew Research Center, o percentual dos que se declararam "sem religião" em 2012 é de 19,6\% dos americanos, com um percentual de ateus de $2,4 \%$. O interessante é que também lá o agregado da parcela cristã com a parcela dos "sem religião" soma 92,6\%.

Note-se que, conforme sublinhou Clara Mafra, o grupo "sem religião" no Brasil possui um forte componente de pessoas com pouca escolaridade e baixa renda financeira. Ao contrário do que se poderia supor, declarar-se "sem religião" não é a simples expressão de pessoas secularizadas, influência positivista e alto poder aquisitivo. Necessitamos de mais dados para compreender esse grupo. As considerações feitas por Clara Mafra em seu artigo sobre alguns fatores inerentes ao pentecostalismo que explicam, em parte, a declaração de não ter pertença religiosa por parte de algumas pessoas nos ajudam a entender melhor a dinâmica de declarar-se "sem religião". Essa situação poderia, em muitos casos, ser transitória e não definitiva, o que contribuiria para compreender por que o grupo não apresenta um crescimento mais significativo nas ultimas décadas, pois para uma dada pessoa, neste caso, estar "sem religião" no momento do Censo não significa estar "sem religião" no momento seguinte. Devemos também levar em conta a hipótese levantada por Carlos

Debates do NER, Porto Alegre, ANo I4, N. 24, P. 93-98, JUl./DeZ. 2013 
Steil em um Seminário sobre o Censo na PUC-Rio em setembro de 2012. Desde a segunda metade dos anos 60, nos anos pós Concílio Vaticano II, a pastoral católica tornou mais rígido o acesso aos sacramentos, inclusive ao batismo, exigindo cursos, preparação e, em alguns locais, durante certo tempo, até mesmo exigindo a pertença à uma comunidade ou a frequência na paróquia. Essa prática, que visava a reforçar a identidade católica, terminou também por afastar alguns dos chamados "católicos nominais", isto é, pessoas batizadas que se autocompreendiam como católicas, mas que mantinham com a igreja certo distanciamento, sobretudo no que diz respeito à prática sacramental frequente. Produziram-se assim novas gerações inicialmente de pessoas que não fizeram catequese e primeira comunhão, que não casaram na igreja, não batizaram seus filhos e depois, se não se tornaram evangélicas, provavelmente se declaram sem religião.

Após abordar esses três pontos, a título de notas, como comentário ao ótimo e instigante artigo de Clara Mafra, gostaria de ressaltar que as transformações que presenciamos nas últimas décadas no campo religioso brasileiro são sinais significativos de como nossa sociedade se tornou neste período mais complexa e diversificada e de como nela os diferentes sujeitos gozam de autonomia na construção de sua identidade religiosa, sendo cada vez mais importante não a tradição recebida, mas a busca pessoal de sentido.

\section{REFERENCIAS}

(Pew Research Center, "Nones" on the Rise: One-in-Five Adults Have No Religion Affiliation, Pew Research Center's Forum on religion \& Public Life, Washington, 2012. U. S. Religious Landscape Survey. Religious Affliation: Diverse and Dynamic. February 2008, Pew Research Center's Forum on religion \& Public Life, Washington, 2008.) 